\title{
Ultra Short Beam Pulses
}

\author{
von R. E. PIXLEy \\ (Physikinstitut der Universität Zürich)
}

Publikation vorgesehen in Hel. Phys. Acta.

\author{
Les essais de mise en service du réacteur CROGUS du Laboratoire \\ de Génie Atomique de 1'EPF, Lausanne \\ $\operatorname{par}$ A. S. TAI \\ (Laboratoire de Génie Atomique de l'EPF, Lausanne)
}

Les essais de mise en service du réacteur CROCUS ont été effectués avec succès. Les essais d'approche sous-critique consistent à ajouter progressivement des barres d'U-métal autour du cœur initial de 292 barres d'UO ${ }_{2}$ jusqu'à une réactivité maximale de $800 \mathrm{pcm}$ environ. Les essais d'approche critique procèdent à un ajustement fin du nombre de barres d'U-métal, de manière à atteindre la criticité au niveau nominal prévu. Pour chaque chargement, on fait varier le niveau du modérateur $\left(\mathrm{H}_{2} \mathrm{O}\right)$ par pas, à partir d'un niveau intermédiaire jusqu'au niveau nominal. La réactivité $\varrho$ est déterminée par la méthode des neutrons pulsés. Les mesures de l'inverse du taux de comptage permettent une bonne prévision sur la hauteur critique du modérateur. La criticité est atteinte avec le chargement de 292 barres d'UO ${ }_{2}$ plus 200 barres d' $U$ métal, pour une hauteur d'eau de $98,5 \mathrm{~cm}$.

\section{Application of the Coulomb Approximation to the Rydberg Transitions of the NO Molecule}

\author{
by R. Gallusser and K. Dressier \\ (Laboratorium für physikalische Chemie, ETH Zürich)
}

Theoretical dipole transition strengths have been calculated for all of the important emission systems between Rydberg (Ry) states in the NO molecule. A qualitative discussion of some of these transition moments has recently been given by Jungen [1], and approximate oscillator strengths have been derived by Wray [2] from intensity measurements in high-temperature air.

The Ry MO's of NO have been represented in a one-center basis of atomic Ry orbitals whose radial factors are defined by the effective quantum number $n^{*}$ in the Coulomb approximation [3]. The MO coefficients given in Table 1 were derived from the following considerations: The deviation of the molecular Ry orbitals from spherical symmetry is incorporated by superposition of basis orbitals with different $l$-values, which is most important in the states $E$ and $H$ (mixing of $l=0$ and $l=2$ ) as described by Jungen. Complete $l$-uncoupling has been assumed for the states $H^{2} \Sigma^{+}$and $H^{\prime 2} \Pi^{+}$, i.e. mixing of $m_{l}=0$ and $(+1)+(-1)$, as established experimentally for all but the lowest $J$-values by Huber and Miescher [4]. To account for the observations of the $E-A$ and $H, H^{\prime}-A$ transitions $[5,6]$, the $A$ state has been represented by an admixture of $l=1$ to its principally $l=0$ Ry orbital. The $2 \pi$ orbital occupied by the 